\title{
Contribution of gastrointestinal transit and pouch characteristics in determining pouch function
}

\author{
P A Goldberg, M A Kamm, R J Nicholls, G Morris, K E Britton
}

\begin{abstract}
Aim-To determine the contributions of gastrointestinal transit and pouch characteristics to bowel frequency in patients with an ileoanal reservoir and no pouchitis. Methods-Twenty one patients who had undergone restorative proctocolectomy, with ileostomy closure at least eight months previously, and who had no history of pouchitis were recruited. They were prospectively classified on the basis of their bowel frequency: 11 patients had good pouch function (bowel frequency less than six per day) and 10 had poor function (bowel frequency more than six per day). Gastrointestinal transit was studied using a dual isotope technique and anal and pouch physiological examination was performed on all patients.
\end{abstract}

Results-Lag phase, $25 \%$ and $50 \%$ gastric emptying, small bowel transit time, and $10 \%$ and $50 \%$ pouch filling times, all for solids and liquids, were not significantly different between patients with good and poor function. Anal manometry and pouch and anal electrical sensitivity were also similar in the two groups. The volume of air and water required to elicit an initial sensation and the urge to defaecate were similar in both groups, but the maximum tolerated volume to both air $(525 v 245 \mathrm{ml}$, $\operatorname{good} v$ poor function, median values) and water (625 $v 370 \mathrm{ml})$ infusion was significantly (both $p<0.02$ ) lower in patients with poor function.

Conclusion-Maximum tolerated volume in the pouch, which may reflect pouch size, sensitivity, compliance, or a combination of these is the major determinant of pouch function. Gastrointestinal transit does not seem to be an important determinant of function.

(Gut 1997; 40: 790-793)

Keywords: ileoanal pouch, ileoanal reservoir, transit time, function, radioisotope.

P A Goldberg

M A Kamm

R J Nicholls

Department of Nuclear Medicine, St Mark's Hospital, London

G Morris

K E Britton

Correspondence to:

Dr M A Kamm,

St Mark's Hospital,

Northwick Park, Watford

Road, Harrow, Middlesex

HA1 3UJ.

Accepted for publication

20 February 1997 to pouchitis. In the remainder there appears to be a functional problem without a clear inflammatory basis. This functional abnormality is usually attributed to abnormalities of pouch behaviour, and the most common causes are thought to be a small or non-
More than $80 \%$ of patients with an ileoanal reservoir have a stool frequency of less than six compliant pouch, the latter sometimes relating to perioperative sepsis.

An alternative explanation for increased bowel frequency or stool output could relate to the rate of gastrointestinal transit proximal to the pouch. We have previously investigated small bowel motor function in patients with good and poor pouch function, using 24-hour ambulatory manometric assessment. ${ }^{3}$ Patients with poor pouch function had a significantly greater number of migrating motor complexes during the fasting period than patients with good function. There was no difference in the radiological pouch size or stool output between the two groups of patients, suggesting that a small bowel motor abnormality may have been important in determining the functional outcome.

Although this last study investigated small bowel motor activity, the final consequence of such an abnormality, and the means by which symptoms are generated, is likely to be an alteration in the transit of intestinal contents. We have therefore investigated gastrointestinal transit in patients with good and poor bowel frequency after pouch creation, the latter group having an apparently good anatomical result and no pouchitis.

\section{Methods}

SUBJECTS

Twenty one patients who had undergone restorative proctocolectomy with closure of their temporary ileostomy at least eight months previously were recruited. All patients had been operated on by one surgeon (RJN). Patients were prospectively selected and classified on the basis of their pouch function. Those with good pouch function were defined as having a bowel frequency of less than six times per day and less than or equal to once per night, were fully continent, able to empty their pouch spontaneously, and defer defaecation for more than 15 minutes. Those with poor function had a bowel frequency of more than six times per day and once per night. In this study those with poor function were selected to have full continence and spontaneous emptying, to exclude the effect of analpouch dysfunction as the cause of symptoms.

We studied 11 patients (eight males, mean age 43 years, range 27-62) with good function and 10 patients (six males, mean age 43 years, range 27-60) with poor function. No patient had current or previous endoscopic or histological evidence of pouchitis. 
TABLE I Patient details

\begin{tabular}{lll}
\hline & $\begin{array}{l}\text { Good function } \\
(n=11)\end{array}$ & $\begin{array}{c}\text { Poor function } \\
(n=10)\end{array}$ \\
\hline $\begin{array}{l}\text { Disease } \\
\quad \text { Familial adenomatous polyposis }\end{array}$ & 0 & 2 \\
$\quad$ Ulcerative colitis & 11 & 8 \\
$\begin{array}{l}\text { Time from closure of ileostomy: } \\
\text { median (1-3) months }\end{array}$ & $44(26-82)$ & $43(35-73)$ \\
Nocturnal defaecation & 2 & 9 \\
$\quad$ Always & 4 & 1 \\
$\quad$ At times & 5 & 0 \\
Never & & 6 \\
Pouch type & 8 & 4 \\
W & 1 & 0 \\
J & 1 & 0 \\
$\quad$ Unknown & 1 & $9 \cdot 0(7-9)$ \\
Number of stools per 24 hours & $3(3-5)$ & $6 \cdot 5(5-8)$ \\
Stools during awake period & $3(3-4)$ & $1 \cdot 5(1-3)$ \\
Stools during sleep period & $0(0-1)$ & \\
\hline
\end{tabular}

Stool frequency is median (interquartile range: $\mathrm{q} 1-\mathrm{q} 3$ ) number of stools for each of the patient groups. All other data refer to the number of patients with that disease, pouch type, or presence of nocturnal defaecation.

Stool frequency $(p<0.0005)$ and nocturnal defaecation $(p<0.02)$ differed significantly between the two groups. applied with slowly increasing current from zero until the subject experienced an initial sensation. The measurement was repeated three times and the lowest reading taken as the sensory threshold. ${ }^{5}$

Pouch sensitivity to electrical sensation-This was measured using the same electrode placed $6 \mathrm{~cm}$ above the upper end of the anal sphincter and the process repeated using a stimulus of 10 $\mathrm{Hz}$ and $500 \mu$ second duration. ${ }^{5}$

Gastrointestinal transit study

All constipating medication was stopped 48 hours prior to the study. All subjects fasted from midnight prior to the start of the study. Gastric emptying, small bowel transit, pouch filling, and pouch emptying were studied.

At 10 am on the day of the study subjects ate a pancake containing $10 \mathrm{MBq}$ indium-111 bound to $5 \mathrm{~g}$ Amberlite IR 120 anion exchange resin microspheres (average diameter $0.7 \mathrm{~mm}$, range $0.5-1.0 \mathrm{~mm}$ ) (Amersham International, UK) to study the solid phase. To study the liquid phase, $195 \mathrm{ml}$ orange juice containing 40 $\mathrm{MBq}$ technetium-99m bound to antimony sulphide colloid was ingested. All subjects ate the meal within 10 minutes and then drank the orange juice. This technique has been extensively validated previously, and has been shown to separate clearly liquid and solid emptying. ${ }^{6}$

The whole body dose of radiation was 0.06 rad for ${ }^{111}$ In (effective dose equivalent 3.0 $\mathrm{mSv}$ ) and $0.014 \mathrm{rad}$ for ${ }^{99 \mathrm{~m}} \mathrm{Tc}$ (effective dose equivalent $0.5 \mathrm{mSv}$ ). The caloric content of the pancake was $630 \mathrm{kcal}$ and contained $80 \mathrm{~g}$ carbohydrate, $27 \mathrm{~g}$ fat, and $18 \mathrm{~g}$ protein. This meal was intentionally designed to approximate normal food in its bulk, total caloric content, and proportion of fat, protein, and carbohydrate.

The pancake and orange juice were scanned before the meal was consumed to derive a correction factor for the overlapping energy spectra of each isotope. Patients stood in front of the camera so that the whole abdominal content could be monitored. Scanning of the subject began within five minutes of completing the meal. Anterior and posterior static images were collected for 30 seconds every five minutes for the first hour, and then at 15 minute intervals until all of the solid and liquid meal had entered the ileoanal pouch or for a maximum of four hours, whichever came first. The gamma camera (Siemens model ZLC7500 , Germany) had a large field-of-view head and was fitted with a high resolution, medium energy, parallel hole collimator. Dual radioisotope simultaneous scanning was carried out with the gamma camera peaked for $250 \mathrm{keV}$ with a $40 \%$ window for the ${ }^{111}$ In (the $172 \mathrm{keV}$ peak was ignored) and $140 \mathrm{keV}$ with a $20 \%$ window for the ${ }^{99 \mathrm{~m}} \mathrm{Tc}$. The combination of this spectral width analysis and the appropriate collimation reduced the effects of Compton scattering. The counts were corrected for radioisotope decay. The subjects were not allowed to eat or drink until all data were collected.
Anal sensitivity to electrical stimulation-This was measured using a bipolar ring electrode (Dantec 21L1OUK) mounted on a Foley urinary catheter which was placed in the midanal canal and connected to a constant current stimulator (Neuromatic 2000 M/C, Dantec UK). A $5 \mathrm{~Hz}, 100 \mu$ second stimulus was 


\section{DATA ANALYSIS}

Regions of interest were created for the stomach and ileoanal pouch based on visual assessment of sequential scans. Time-activity curves for these two regions were generated for each subject for the solid and liquid phases. In addition the lag phase of gastric emptying was assessed visually on sequential scans, as was the first entry of solid and liquid into the pouch.

The geometric mean was calculated to provide the radioisotope concentration at each time, using anterior and posterior images, to eliminate the effect of tissue attenuation. Decay of the radioisotope was taken into account when determining regional isotope concentrations. Compton scatter, that is, the overlap of the energy spectra for ${ }^{111}$ In and ${ }^{99 \mathrm{~m}} \mathrm{Tc}$, was also corrected for. ${ }^{7}$

\section{Gastric emptying}

Time-activity curves were created for liquid and solid emptying after creation of a region of interest drawn around the stomach. The lag phase for solid emptying was defined as the period of time between the end of the meal (when data acquisition started) and the time when $5 \%$ of the ${ }^{111}$ In had left the stomach. For statistical analysis of gastric emptying, the lag

TABLE II Anal and pouch manometry, and sensitivity to electrical stimulation and distension

\begin{tabular}{lccc}
\hline & $\begin{array}{l}\text { Good function } \\
(n=10)\end{array}$ & $\begin{array}{l}\text { Poor function } \\
(n=10)\end{array}$ & $p$ Value \\
\hline Maximum resting pressure (mm Hg) & $70(60-100)$ & $60(60-80)$ & $0 \cdot 50$ \\
Maximum voluntary contraction (mm Hg) & $150(120-220)$ & $160(140-325)$ & $0 \cdot 60$ \\
Distension by air (ml) & $65(40-150)$ & $85(40-130)$ & $1 \cdot 00$ \\
$\quad$ Threshold & $250(150-450)$ & $175(140-250)$ & $0 \cdot 30$ \\
Urge & $525(450-640)$ & $245(200-350)$ & $0 \cdot 02$ \\
$\quad$ Maximum tolerated volume & $212(70-300)$ & $77 \cdot 5(60-220)$ & $0 \cdot 30$ \\
Distension by water (ml) & $400(225-450)$ & $235(120-320)$ & $0 \cdot 09$ \\
$\quad$ Threshold & $625(560-760)$ & $370(200-440)$ & $0 \cdot 02$ \\
Urge & $87 \cdot 5(50-150)$ & $60(28-75)$ & $0 \cdot 09$ \\
Maximum tolerated volume & $4 \cdot 45(3 \cdot 2-7 \cdot 6)$ & $6 \cdot 1(4-7 \cdot 2)$ & $0 \cdot 50$ \\
dv/dp (ml/mm Hg) & $46(35-65)$ & $70(42-76)$ & $0 \cdot 40$ \\
Anal sensation (mA) & & & \\
Pouch sensation (mA) & & & \\
\hline
\end{tabular}

Values expresses as median (interquartile range: $\mathrm{q} 1-\mathrm{q} 3$ ).

TABLE III Gastric emptying and intestinal transit in patients with good and poor function

\begin{tabular}{|c|c|c|c|}
\hline & $\begin{array}{l}\text { Good function } \\
(n=10)\end{array}$ & $\begin{array}{l}\text { Poor function } \\
(n=10)\end{array}$ & $p$ Value \\
\hline \multicolumn{4}{|c|}{ Gastric emptying } \\
\hline $\begin{array}{l}25 \% \\
50 \%\end{array}$ & $\begin{array}{c}35(20-45) \\
105(75-105)\end{array}$ & $\begin{array}{l}37 \cdot 5(25-75) \\
90(90-135)\end{array}$ & $\begin{array}{l}0 \cdot 4 \\
0 \cdot 3\end{array}$ \\
\hline \multicolumn{4}{|l|}{ Solid } \\
\hline $\begin{array}{l}25 \% \\
50 \%\end{array}$ & $\begin{array}{l}75(50-105) \\
127 \cdot 5(120-157 \cdot 5)\end{array}$ & $\begin{array}{l}105(60-165) \\
165(150-180)\end{array}$ & $\begin{array}{l}0 \cdot 3 \\
0 \cdot 2\end{array}$ \\
\hline \multicolumn{4}{|c|}{ First duodenal entry } \\
\hline $\begin{array}{l}\text { Liquid } \\
\text { Solid }\end{array}$ & $\begin{array}{c}5(5-5) \\
15(10-25)\end{array}$ & $\begin{array}{c}5(5-10) \\
22 \cdot 5(20-25)\end{array}$ & $\begin{array}{l}0 \cdot 5 \\
0 \cdot 1\end{array}$ \\
\hline \multicolumn{4}{|c|}{ Time to first pouch filling } \\
\hline $\begin{array}{l}\text { Liquid } \\
\text { Solid }\end{array}$ & $\begin{array}{r}60(30-120) \\
105(75-135)\end{array}$ & $\begin{array}{l}75(55-120) \\
97 \cdot 5(90-150)\end{array}$ & $\begin{array}{l}0 \cdot 2 \\
0 \cdot 7\end{array}$ \\
\hline \multicolumn{4}{|c|}{ Proportion of radioisotope in the pouch at $50 \%$ gastric emptying } \\
\hline $\begin{array}{l}\text { Liquid } \\
\text { Solid }\end{array}$ & $\begin{array}{l}18(11-22 \cdot 9) \\
12 \cdot 3(8-14 \cdot 3)\end{array}$ & $\begin{array}{l}17(8 \cdot 4-28) \\
17.6(10 \cdot 8-23.5)\end{array}$ & $\begin{array}{l}0 \cdot 7 \\
1 \cdot 0\end{array}$ \\
\hline \multicolumn{4}{|c|}{ Time for $10 \%$ of ingested meal to enter the pouch } \\
\hline $\begin{array}{l}\text { Liquid } \\
\text { Solid }\end{array}$ & $\begin{array}{c}75(55-90) \\
105(90-120)\end{array}$ & $\begin{array}{r}97 \cdot 5(75-150) \\
105(105-195)\end{array}$ & $\begin{array}{l}0 \cdot 3 \\
0 \cdot 4\end{array}$ \\
\hline \multicolumn{4}{|c|}{ Time for $50 \%$ of ingested meal to enter the pouch } \\
\hline $\begin{array}{l}\text { Liquid } \\
\text { Solid }\end{array}$ & $\begin{array}{l}225(100-250) \\
232.5(217.5-260)\end{array}$ & $\begin{array}{l}260(192 \cdot 5-315) \\
232 \cdot 5(165-300)\end{array}$ & $\begin{array}{l}0.5 \\
0.9\end{array}$ \\
\hline
\end{tabular}

Numbers are the median time in minutes (interquartile range: $q 1-q 3$ ), except for the proportion of radioisotope in the pouch at $50 \%$ gastric emptying. phase of solid emptying and the time taken to empty $25 \%$ and $50 \%$ of each of the two phases of the meal were determined.

\section{Small bowel transit}

Inspection of all the images from a study enabled the pouch to be defined separate from the ileum, although at times it was possible that this included some terminal prepouch ileum due to overlap. The time of arrival of the liquid and solid phases in the region of the reservoir was determined.

\section{Statistical calculations}

All data were treated as non-parametric and the Mann-Whitney $U$ test was used to assess statistical differences; $p<0.05$ was considered statistically significant.

\section{Results}

Pouch and anal physiological data were available for analysis in $20 / 21$ subjects (Table II). The anal resting pressure and maximum voluntary contraction pressures were similar in the two groups of patients. The anal sensory threshold to electrical stimulation was also similar in the two groups. When air and water were infused into a balloon placed in the pouch, the volume of air and water required to elicit an initial sensation and the urge to defaecate were similar in both groups, but the maximum tolerated volume (discomfort) was significantly less in those subjects with poor function (Table II).

There was no statistical difference between the two patient groups for the time taken for the stomach to empty $25 \%$ or $50 \%$ of the liquid or solid component of the meal. Similarly, the times taken for solid and liquid to enter the duodenum and to reach the pouch were similar. The times taken for $10 \%$ and $50 \%$ of the meal to enter the pouch were also similar (Table III).

\section{Discussion}

This study has shown that poor pouch function in the absence of mucosal inflammation does not appear to be related to decreased gastric emptying or small bowel transit time. Although we have previously demonstrated differences in small bowel motor activity between patients with good and poor function, these differences do not appear to equate with differences in transit. This suggests that manometrically measured differences in motor function are not the primary determinant of altered pouch function, but rather may occur simultaneously with changes in pouch function.

Our findings suggest that pouch sensitivity or size, as reflected in a difference in the maximum tolerated volume between the two groups, may be more important determinants of bowel frequency. This correlation of pouch maximum tolerated volume and bowel frequency has been noted previously. ${ }^{8-11}$ Several factors may contribute to a patient's 
tested maximum tolerated volume, including the pouch size, sensitivity, and tone. The measured compliance in this study did not differ between the two patient groups, suggesting that pouch size or sensitivity was the most important factor. In a previous study we demonstrated a difference in the pouch maximum tolerated volume between patients with good and poor function, despite similar radiological measurements of the pouch size on lateral radiographs, suggesting that altered sensation may play a role.

Other factors which may account for differences in function include pouch motility, ${ }^{12}$ the volume of stool passed on each occasion (which may reflect adequacy of pouch emptying), and differences in patient lifestyle and personality. In a previous study we found that the total stool volume did not differ between patients with good and poor function, but the latter group passed smaller volumes more frequently. ${ }^{3}$

In summary, pouch characteristics rather than gastric and small intestinal transit appear to be the most important factors in determining bowel frequency.

We gratefully acknowledge the generous use of the facilities of the Imperial Cancer Research Fund at St Mark's Hospital.
1 Setti-Carraro P, Ritchie JK, Wilkinson KH, Nicholls RJ, Hawley PR. The first 10 years' experience of restorative proctocolectomy for ulcerative colitis. Gut 1994; 35: $1070-5$.

2 McIntyre PB, Pemberton JH, Wolff BG, Beart RW, Dozois RR. Comparing functional results one year and ten years after ileal pouch-anal anastomosis for chronic ulcerative colitis. Dis Colon Rectum 1994; 37: 303-7.

3 Groom JS, Kamm MA, Nicholls RJ. Relationship of small bowel motility to ileoanal reservoir function. Gut 1994 35: 523-9.

4 Rogers J, Laurberg S, Misiewicz JJ, Henry MM, Swash M. Anorectal physiology validated: a repeatability study of the motor and sensory tests of anorectal function. $\mathrm{Br} \mathcal{F}$ Surg 1989; 76: 607-9.

5 Kamm MA, Lennard-Jones JE. Rectal mucosal electrosensory testing - Evidence for a rectal sensory neuropathy in idiopathic constipation. Dis Colon Rectum 1990; 33: in idiopathis.

6 Mather SJ, Ellison D, Nightingale J, Kamm M, Britton KE. The design of a two-phase radiolabelled meal for gastric

7 Horowitz M, Akkermans LMA. Scintigraphic measurement of gastric emptying. In: Read NW, ed. Gastrointestinal motility. Which test? Petersfield: Wrightson Biomedical Publishing Ltd, 1989: 73-89.

8 Scott NA, Pemberton JH, Barkel DC, Wolff BG. Anal and ileal pouch manometric measurements before ileostomy closure are related to functional outcome after pouch-anal anastomosis. $B r \mathcal{F}$ Surg 1989; 76: 613-6.

9 Nicholls RJ, Lubowski DZ. Restorative proctocolectomy: the four loop (W) reservoir. $B r \mathcal{F}$ Surg 1987; 74: 564-6.

10 Nicholls RJ, Moskowitz RI Shepherd NA. Restorative proctocolectomy with ileal reservoir. Br f Surg 1985; 72(suppl): S76-S79.

11 Nicholls RJ, Pezim ME. Restorative proctocolectomy with ileal reservoir for ulcerative colitis and familial adenomatous polyposis: a comparison of three reservoir designs. Br $\mathcal{F}$ Surg 1985; 72: 470-4.

12 Levitt MD, Kamm MA, Groom J, Hawley PR, Nicholls RJ Ileoanal pouch compliance and motor function. $B r f$ Surg 1992; 79: 126-8. 